\title{
La luz difícil de Tomás González y La balada del pajarillo, de Germán Espinosa: dos novelas de artista colombianas en el siglo XXI
}

\author{
La luz difícil by \\ Tomás González, \\ and La balada del \\ pajarillo by Germán \\ Espinosa: Two \\ Colombian Artist \\ Novels in the 21st \\ Century
}

La luz difícil, de

Tomás González, e La balada del

pajarillo, de

Germán Espinosa:

dois romances de

artistas colombianos

no século XXI

\section{(c) $($ i) (2) \\ Para citar este artículo \\ Herrera Rodríguez, C. (2021). La luz difícil de Tomás González y La balada del pajarillo de Germán Espinosa: dos novelas de artista colombianas en el siglo xxı. Folios, (54). https://doi.org/10.17227/folios.54-12028}

* Magister en Hermenéutica Literaria de la Universidad Eafit. Docente del programa de Licenciatura en Humanidades y Lengua Castellana de la Facultad de Educación de la Universidad de San Buenaventura, Medellín, Colombia.

Correo: camilo.herrera@usbmed.edu.co

Artículo recibido

$07 \cdot 07 \cdot 2020$

Artículo aprobado $28 \cdot 01 \cdot 2021$ 


\title{
Resumen
}

Este artículo de reflexión analiza dos novelas: La luz difícil de Tomás González, así como La balada del pajarillo de German Espinosa, desde el punto de vista de la novela de artista o Künstlerroman. El análisis de ambas narraciones busca proponer una caracterización del artista como un ser inmerso en la sociedad, a veces consagrado o marginado, creador activo o pasivo, teniendo en cuenta, además, otras obras representativas de este tipo de novela. Lo anterior, con el objetivo de ilustrar los aspectos característicos de dos ficciones colombianas que bien pueden enmarcarse en una misma tradición novelística: la novela de artista. A saber, los orígenes de la novela de artista en relación con las propuestas de González y Espinosa; la apreciación del arte como inherente al artista/héroe de la novela; el concepto de la novela como ejercicio liberador y catártico del artista.

\author{
Palabras clave \\ Tomás González; La luz difícil; Germán Espinosa; La balada del \\ pajarillo; novela de artista (Künstlerroman)
}

Abstract

This reflection article is intended to analyze two novels: La luz difícil by Tomás González, as well as La balada del pajarillo by German Espinosa, from the point of view of the artist novel or Künstlerroman. The analysis of both narratives tries to propose a characterization of the artist as one immersed in society, occasionally acclaimed or marginalized, active or passive creator, considering, as well, other representative works of this type of novel. This, with the intention of showing the characteristic of two Colombian fictions that could be placed into the same novelistic tradition: the artist novel. Namely, the origins of the artist's novel in relation to the proposals of González and Espinosa; the appreciation of art as inherent in the artist/hero of the novel; the concept of the novel as a liberating and cathartic exercise for the artist.

\section{Keywords}

Tomás González; La luz difícil; Germán Espinosa; La balada del pajarillo; artist-novel (Künstlerroman)

\section{Resumo}

Este artigo analisa dois romances: La luz difícil de Tomás González, e La balada del pajarillo de Germán Espinosa, do ponto de vista do romance do artista ou Künstlerroman. A análise de ambas as narrativas busca propor uma caracterização do artista como um ser imerso na sociedade, às vezes consagrado ou marginalizado, criador ativo ou passivo, levando em consideração também outras obras representativas desse tipo de romance. 0 anterior com o objetivo de ilustrar os aspectos característicos de duas ficções colombianas que podem muito bem ser enquadradas na mesma tradição romanesca: 0 romance do artista. A saber, as origens do romance do artista em relação às propostas de González e Espinosa; a apreciação da arte como inerente ao artista/herói do romance; a concepção do romance como exercício libertador e catártico do artista.

\section{Palavras chave}

Tomás González; La luz difícil; Germán Espinosa; La balada del

pajarillo; romance do artista (Künstlerroman) 


\section{Introducción}

La novela de artista (a partir de este punto, la novela), que puede rastrearse en Los años de aprendizaje de Wilhelm Meister de Goethe, propone una concepción de la vida característica del artista, ligada a la creación intelectual y alejada de los convencionalismos de la vida social; postulado debido, quizás, a que la figura misma de este, desde el periodo clásico hasta la actualidad, comparte esa problemática existencial que lo lleva, por las funciones que tiene frente a la sociedad, a contradecir su modo de vida particular, lo que se hace evidente en el aislamiento del mundo que lo rodea (Álvarez, 1993, pp. 293-294).

En la novela, el artista se debate entre dos maneras de afrontar la creación artística: una vida consagrada al arte que lo deja recluido en una torre de marfil en la cual "la vida es reemplazada por el arte, y el arte se convierte en un ritual sagrado" (Beebe, 1964, p. 114), o una vida de recorrido, de experiencia, ligada al proceso artístico como sinónimo de vida, como una suerte de manantial de una fuente (o, si se prefiere, fontana) sagrada (pp. 114-115). Dos formas de la novela que se distancian debido a la manera de asimilar el acto creativo, pero que se asemejan, en la medida en que el artista no alcanza a alejarse de su idiosincrasia:

Entonces, lo que importa para la creación del arquetipo no es la actividad del artista sino su actitud vital. Generalmente sensitivo, controvertido y egocéntrico, pasivo y distante del mundo que lo rodea, distraído o poseído. Lo que los consagra como artistas es su relación con sus mundos respectivos, es decir, su relación con la sociedad. (Álvarez, 1993, pp. 295-296)

La relación entre artista y sociedad constituye una característica clave para la comprensión y análisis de la novela. El sujeto artístico se siente liberado de la vida social, rechazándola totalmente o abrazándola con intensidad. Se presentan, entonces, simples rasgos del artista que adoptan la apariencia de aquellos de la realidad, como "la ausencia de un hogar, el desarraigo, la precariedad de las cosas materiales y los paraísos artificiales" (Quintero, 2010, p. 19) para dar cuenta de la totalidad de él. La importancia de estos rasgos es identificada por Herbert Marcuse (2007), filósofo alemán perteneciente a la escuela de Fráncfort, quien se refiere a la novela de esta manera:

La novela de artista debería ser, por consiguiente, una novela en la cual un artista sea tratado en su entorno y como poseedor de una forma de vida característica. Por lo tanto, el lugar histórico de la novela de artista dentro del arte literario y épico solo es posible si la propia naturaleza de un artista significa tener una forma peculiar de vida que no sea coherente con la de la gente en general, esto es, cuando el arte ya no sea la expresión inmanente y necesaria en la vida entera de la comunidad. (p. 72)

Con estas premisas y a la luz de estas consideraciones, La luz difícil de Tomás González y La balada del pajarillo de Germán Espinosa pueden considerarse como parte de esta tradición novelística, puesto que las características del artista son rastreables en ambas obras: ya sea en los conflictos creativos de los protagonistas, sus angustias personales, sus libertades o, simplemente, en la manera como el romance los envuelve en un halo de excesiva confianza o de insoportable amargura.

\section{Caracterización del artista}

David, en La luz difícil, es presentado como un pintor contemporáneo que va recorriendo, en su vida profesional, etapas que lo llevan de ser un artista joven sin reconocimiento alguno hasta volverse uno consagrado. Braulio Cendales, en La balada del pajarillo, es descrito, por el contrario, como un pintor, restaurador y crítico de arte que se encuentra en la plenitud de su carrera profesional y que va descendiendo hacia el abismo de la decadencia personal y profesional. Tal contraste entre ambas obras permite revisar la manera como estos artistas están

Las traducciones de las obras en inglés en todo el artículo son del autor y se elaboran con fines académicos. 
en conflicto con la sociedad, sus actitudes frente a la marginación o la consagración de su obra y los efectos de ello en sus experiencias creadoras.

David reconoce lo trivial que era en su juventud el efecto de la sociedad en su obra, mientras que el lugar de trabajo era de vital importancia para su acto creativo: el encierro, el silencio, el espacio y la luz, condiciones que se debaten, a su vez, con constantes cambios de ánimo que son reflejo del desarraigo al que el artista se somete al abandonar su patria, en la que no encontraba tranquilidad, "en busca del agua y de la luz" (González, 2011, p. 15) David no es realmente, ni en sentido estricto, un artista que rompa con la sociedad, aunque en principio necesite de esa ruptura para comprender lo fútil de tal empeño: "Fueron difíciles los primeros meses en Nueva York, bien difíciles, no para Sara y los niños, para mí, que tenía tanto requisito de luz, espacio, silencio y demás tonterías que uno se inventa a esa edad para complicarse la vida" (González, 2011, p. 17).

Cendales, por su parte, es presentado en La balada del pajarillo como un hombre que sabe vivir en sociedad pero que no pierde oportunidad para despotricar de ella: del público que lee sus columnas, de las exposiciones de arte y las obras de cada pintor criollo, de las caras de las personas que él asocia con el mundo animal, del mundillo literario que frecuenta los bares (y eso incluye poetas consagrados y en ascenso): "Lo acompañaban dos jóvenes poetas, harto clasificados ya por mi habitual escrúpulo, cuyos libros primigenios, haría no más de un año, habían sido celebrados sin ninguna mesura por esa crítica de compadrazgo que se ejerce entre nosotros" (Espinosa, 2000, p. 66). Para Cendales, no hay necesidad de romper con la sociedad puesto que él está por encima de ella. Es innegable, sin embargo, la erudición elevada del personaje y la facilidad como se desenvuelve tanto en la composición de su columna semanal como en el oficio de restaurador.

Estos aspectos de la personalidad de ambos personajes constituyen un rasgo claro que va definiendo el futuro de David y Braulio en las respectivas novelas. Por un lado, un pintor como David que, a pesar de ciertos rasgos egoístas y solitarios, encuentra en su vida familiar un apoyo para configurar su obra. Por otro lado, un Braulio egocéntrico, paranoico y cobarde, que en ciertos momentos se alimenta de sus propias obsesiones. Existen, ciertamente, características de una personalidad única en ellos, necesarias para que la novela trascienda, puesto que

[...] solo en el caso en el cual el artista se convierte en una personalidad particular, como el representante de una forma de vida propia que no es la que, fundamentalmente, comparte con aquellos a su alrededor, podría convertirse en el héroe de la novela. (Marcuse, 2007, p. 74)

El caso de Wilhelm Meister, en la novela de Goethe, empieza a moldear la manera como el artista afronta la sociedad. Cabe aclarar que Los años de aprendizaje de Wilhelm Meister es considerada, sobre todo, una novela de aprendizaje (Bildunsgsroman). Sin embargo, la manera como el texto introduce los conflictos del artista permiten que se entienda dicha obra como un prototipo para las novelas que vendrían a continuación, ya que "Bildung [aprendizaje] se relaciona con la fundación de un nuevo paradigma, poético, filosófico y científico, algo más amplio y ambicioso que un programa de autoayuda individual" (Maas, 2002, p. 15). Es claro, siguiendo lo anterior, encontrar en Wilhelm una constante duda que lo lleva a pensar, en palabras del narrador, que "el corazón y la imaginación de Wilhelm lo arrastraban hasta el teatro como su entendimiento y su razón lo alejaban de este" (Goethe, 2003, p. 189).

La figura del artista consagrado o marginado es evidente tanto en La luz difícil como en La balada del pajarillo. David asume la consagración de su obra como una necesidad para su sustento y el de su familia, mientras que la crítica de su arte es algo que, posterior al accidente de Jacobo, no tiene importancia para él. Braulio, en cambio, entiende que su profesión de crítico de arte y restaurador, sumada a ocasionales incursiones como tratante de obras de arte, le permiten darse la vida que él anhela o que, por lo menos, puede tener hasta que la obsesión y la decadencia se lo permitan. 
Para comprender lo anterior, es preciso revisar la trama de ambas novelas. La luz difícil narra los recuerdos que David, un artista retirado, tiene de su vida artística, su entorno familiar y el accidente automovilístico de su hijo Jacobo que funciona como el eje conductor de una historia reveladora de la vida y la muerte. Lo hace, años después, desde su casa de campo en una zona rural colombiana: haciéndonos testigos del destino angustioso de Jacobo que se mezcla con la tranquilidad propia de quien se sienta a mirar el pasado con los ojos del presente. La balada del pajarillo, en cambio, propone una historia vertiginosa repleta de elucubraciones intelectuales en la cual Braulio Cendales nos demuestra sus dotes de escritor y artista, casi como un double talent (razón por la cual es, por encima de Primitivo Drago, el artista-héroe), a medida que nos muestra cómo un crítico de arte reconocido se obsesiona de manera tal con una mujer que llega a perder su prestigio hasta el punto de llegar a contar su historia desde la cárcel.

Mencionadas las tramas, es prudente, ahora, enfocarse en los detalles. Tras su viaje a Estados Unidos, David considera importante vender sus obras y ser respetado por la crítica hasta que, con la improvista fatalidad de Jacobo, deja a un lado esas necesidades de dinero y fama por considerarlas despreciables. Su relación con los críticos es, de igual manera, una carga innecesaria y en extremo fastidiosa, como lo hace saber al referirse a las entrevistas que concede: "Me desesperan, en cambio, con preguntas tediosas y difíciles de contestar sobre el Post-esto y el Post-aquello o sobre el Neo-esto y el Neo-de lo de más allá” (González, 2011, p. 64).

Ya sea al volante de un Alfa Romeo, discutiendo sutilezas intelectuales en compañía de los que para él son falsos intelectuales o vanagloriándose de sus obras de arte y su biblioteca, Braulio Cendales se nos antoja, aunque consagrado profesionalmente, un ser arrogante. En claro contraste con el ascenso del pintor Primitivo Drago, su posterior decadencia se traza en el inevitable y ostensible descenso: la escena descabellada en la exposición de Drago, el despido de la revista, las humillaciones de la cárcel, la impotencia sexual, la drogadicción y el asesinato. Cendales, en uno de sus constantes cuestionamientos, se pregunta:
¿En qué precipicios se había hundido este Braulio Cendales que, hace apenas año y pico, era un influyente crítico de arte, que cortejaba mujeres muy bellas, era dueño de un formidable Alfa Romeo, asistía a la ópera o al ballet, restauraba pinturas coloniales, gobernaba a la perfección cualquier cantidad de licor, poseía una costosa colección de cuadros y una envidiable biblioteca? (Espinosa, 2000, p. 460)

Las angustias acerca de la consagración y el fracaso en $\mathrm{La}$ luz difícil se ven claramente interrumpidas debido a un evento fatídico en la vida de David. Como si fuera esta, quizás, la razón por la cual el artista puede producir sin que la respuesta de la sociedad o el mundillo artístico afecten su temperamento. Cendales, en cambio, reniega de su decadencia, consciente de que no hay marcha atrás a pesar de que su amigo Blanquiset lo amonesta, pues durante toda su vida, Cendales "no había hecho sino desperdiciar las altas dotes de pintor que poseía" (Espinosa, 2000, p. 444). Muere, además, sin producir una obra más significativa que aquel descubrimiento, de la Dama Blanca, oculto en una Virgen del Amparo. Sin embargo, la producción artística no es una característica necesaria en la novela:

El éxito o incluso la producción artística no son requerimientos del protagonista de una Künstlerroman. De hecho, [Beebe] asegura que la mayoría de los protagonistas-artistas son solo artistas potenciales y algunos ni siquiera están identificados como artistas pero son, obviamente, sustitutos de sus autores. Por consiguiente, según Beebe, el temperamento del artista es más imprescindible para definirlo como artista que cualquier otra cosa. (Garrard, 2009, pp. 15-16)

Los primeros rasgos de la anterior cita pueden identificarse en la novela Los años de aprendizaje de Wilhelm Meister, debido al constante desconcierto con el proceso creativo y con el resultado de sus obras, especialmente con la adaptación que hace de Hamlet. Por eso, en ocasiones, se debate entre seguir 
las raíces burguesas que tiene como herencia o una vida al servicio del arte, al punto de considerar el abandono total de su obra "porque un poema o es perfecto o no tiene derecho a existir, pues aquel que no tiene ninguna capacidad para hacer lo mejor debe abstenerse de practicar el arte y no debe dejarse seducir por él" (Goethe, 2003, p. 56). Es comprensible, en la novela de Goethe que, dada su condición de aprendiz, el artista-héroe aún no se perfile en abandonar todo por el arte. Resalta, por lo anterior, la importancia de la obra inconclusa de Novalis, Enrique de Ofterdingen, debido a que en dicha obra empieza a construirse un artista convencido de llevar a cabo una vida de creación:

Enrique de Novalis entrelaza todas las formas de discurso artístico, filosófico y científico para romantizar al mundo. Una estética de poiesis apunta a transformar el mundo y redimirlo a través de la salvación que debe ser descubierta en el arte. (Varsamopolou, 2002, p. 7)

El proceso creativo en La luz difícil se materializa a tal punto que David alcanza el éxito comercial y crítico de su obra, sin que esto quiera decir que la producción artística no signifique un constante vaivén entre la actividad y la pasividad del artista. Este fenómeno se manifiesta en los cambios de domicilio de David que lo llevan a producir intensamente, en la creación de obra tras obra debido a lo que él llama un acto reflejo (González, 2011, p. 22), y en las caminatas en busca de ruinas humanas para proveer de ideas su creación. Sin embargo, el acto creativo se ve interrumpido, o por lo menos deja de ser constante, debido al accidente de Jacobo, y debe contemplar la espuma del ferry como si fuera necesario esperar la conclusión de ese episodio funesto para terminar la obra, o debido a la ausencia de luz, a causa de la ceguera, que lo hace, anhelando la pintura, cambiarla por la reflexión escrita: "quisiera a veces poder volver a pintar. No esos tristes dibujitos que estaba haciendo de reojo cuando decidí dejarlo para más bien ponerme a escribir, sino cuadros grandes, como antes, en los que cabía el mundo" (González, 2011, p. 52).
Al igual que David, Braulio encuentra en la escritura un medio autorreflexivo, catártico y, además, revelador. Por medio de dos manuscritos, el narrador nos da cuenta, en el primero de estos, de una vida creativa que es desafiante y fértil, y que pasa a ser, ya en el segundo manuscrito, decadente y pasiva. Se perfila mordaz cuando se refiere al mundillo del arte; oficioso en el proceso de redacción de su columna; oportunista en lo que a la trata de arte se refiere. Sin embargo, es en la restauración del cuadro de la Virgen del Amparo cuando más activo se le ve, poniendo especial cuidado en rastrear el periodo en que fue hecha la obra, ya fuera por medio de minuciosos estudios en laboratorios o por conjeturas históricas que hace en su taller; descubriendo la fabulosa Dama Blanca que escondía la Virgen del Amparo; o, magistralmente, falsificando esa misma virgen con la ayuda de las fotografías tomadas para la restauración del original. Se nota, en esa obsesión de Braulio por crear una réplica de la Madona, una clara habilidad para desempeñar su oficio (arte, si se prefiere). Por eso, a pesar de sentirse afligido por la ausencia de Mabel Auselou, al culminar la falsificación, su magnum opus, afirma que "la Virgen del Amparo había resucitado" (Espinosa, 2000, p. 368).

Esta manera de afrontar el acto creativo, en ambas obras, es una característica clara de la novela. El artista sobrevive en el arte y encuentra en la creación una verdad liberadora:

El artista protagónico de la novela de artista ya se encuentra a tono con sus ideales; él no conoce la desilusión; su conocimiento de la "verdad" representa una unión más íntima entre sujeto y objeto, un estado indicado, en apariencia, por un rol pasivo en la narrativa. (Hahn, 2002, p. 31)

Dichos ideales pueden rastrearse en la novela de artista colombiana; un ejemplo paradigmático es $D e$ sobremesa, de José Asunción Silva. José Fernández, protagonista de la novela, se debate entre problemáticas artísticas, sociales y morales a medida que comparte su diario repleto de obsesiones y una constante búsqueda de la felicidad por medio del conocimiento, los lujos o el amor. Julio Quintero, 
autor de numerosos artículos referentes a la literatura hispanoamericana, lo explica de esta manera:

La novela de artista, espacio privilegiado donde los creadores justifican su existencia en una sociedad que los objeta por la inutilidad de sus empresas. Este fue el caso del grupo conformado por Petrus Borel, Théophile Gautier y Joris-Karl Huysmans, cuyas obsesiones fueron trasladadas a Latinoamérica a través de la ficcionalización que Silva hizo del escritor inspirado en su novela $D e$ sobremesa. (2010, p. 93)

La relación entre el artista y el amor, también característica en la novela, supone un aspecto común tanto en La luz difícil como en La balada del pajarillo. Ahora, la manera como esta relación influye en los artistas/héroes se manifiesta como un elemento tranquilizador, en el caso de David, y perturbador, en lo apasionado del diálogo amoroso que llevan a cabo Braulio y Mabel. A pesar de sus diferencias, ambas relaciones permiten que el héroe se nutra de ellas para emprender el acto creativo, ya sea en presencia o ausencia de estas musas.

David, pese a unas pocas infidelidades, ve en Sara a una compañera a la cual ama y desea; una mujer que sirve de apoyo a la hora de escuchar sobre sus proyectos artísticos; que detecta las carencias de David, proponiendo palabras de ánimo que él desea escuchar; con la cual puede satisfacer su apetito sexual; que extraña, tras su muerte, en cada atardecer; y a quien remplaza, por lo menos simbólicamente, en la figura de Ángela. Es necesaria, para David, la presencia de Sara como una base en la estructura familiar y, especialmente, en los terrenos en los cuales su vida parece inestable. Más allá de los párrafos que el autor le dedica a Sara, la manera como se refiere a Ángela, quien lo cuida en la vejez, ejemplifica mejor lo anterior: "Ángela, que es ama de llaves y no es mi mujer, pero sí es La Mujer (sin Ella nada ha funcionado jamás)" (González, 2011, p. 74).

La presencia femenina en La balada del pajarillo, a pesar de una que otra esporádica acompañante, se reduce, en esencia, a Mabel Auselou. Aun sin conocerla, Braulio la descubre en la renovada pin- tura de la Cierva Blanca y lo corrobora al conocerla por primera vez en el ballet. De ahí en adelante, él mismo va cavando su tumba: al percibir, en las largas conversaciones que sostiene con Primitivo, esposo de Mabel, la simpatía que ella siente por él; al admirar cada uno de sus poemas que estima resultado de la erudición propia de aquella dama, su par; al declararle su amor, en la sala de su casa, sin importarle que Primitivo pudiera oírlo, y de ahí en más en numerosas ocasiones; al hacerla suya (o al hacerlo suyo) tras la muerte de Vicenta, o en presencia de Primitivo o, desinhibidos, bajo el efecto de la cocaína; al recordarla, posterior a su ausencia, provista de vitalidad, en el cuadro de la Madonna, o carente de ella, en la pintura del pajarillo empotrado; al percibirla como su musa inspiradora, para al final, liberarse de su presencia con un disparo. Tal amor, obsesivo y desenfrenado, no conocía más fin que la muerte física de la poetisa. Sin embargo, será Braulio quien irá agonizando debido a su ausencia, su destino se desprenderá de aquella penuria. Él mismo anticipa, al comenzar el romance con Mabel: "el lector puede comprenderlo con facilidad, un amor tan arrebatado como el que en mí acaba de brotar hacia Mabel Auselou, cancela todo otro encariñamiento" (Espinosa, 2000, p. 124). Eso incluye, sobre todo, el deseo de vivir.

Por un lado, puede evidenciarse cómo la presencia femenina constituye un elemento complementario en la vida personal y artística de David; por otro, Braulio permite que la obsesión amorosa sea más fuerte que su ambición artística, generando así el ejercicio de un poder jerárquico de la musa sobre él. Esta jerarquía puede evidenciarse, de otra manera, en Goethe. La constante desilusión que siente Wilhelm por sus experiencias románticas lo lleva a refugiarse en el arte. Sin embargo, es en el momento en el que decide olvidar el teatro cuando encuentra en Natalia a una compañera que lo libera: "ignoro cuál es el valor de un reino, pero sé que he conseguido una dicha que no merezco y que no cambiaría por nada del mundo" (Goethe, 2003, p. 475). En este caso, la presencia femenina es más fuerte que una vida dedicada, en su totalidad, al arte. 
Un elemento que, nuevamente remitiendo al contexto de la novela colombiana, puede verse, tanto en De sobremesa como en La vorágine de José Eustasio Rivera, en sus dos personajes: José Fernández y Arturo Coba, quienes disfrutan de las mujeres debido al poder que su arte ejerce sobre ellas:

En la obra se señala a Coba como un escritor inspirado por labios del mismo personaje cuando alude al éxito literario que las empresas del Casanare le traerán, y por parte de Barrera, uno de sus lectores. Al igual que en De sobremesa, las mujeres se rinden ante el protagonista. (Quintero, 2010, p. 36)

Tanto en el caso de Wilhelm como en el de las dos novelas colombianas se notan jerarquías entre amor $y$ arte. Sin embargo, es en el "Cuento de hadas de Klingsohr", de Novalis, en donde aquellas jerarquías desaparecen. Lo explica Hahn, de esta manera:

El aspecto más importante de este [cuento de hadas], sin embargo, es la manera en la cual la relación entre poesía y amor se representa de naturaleza intensamente "dialógica", evitando cualquier tipo de jerarquía o dominio entre estas dos energías. (2002, p. 41)

\section{Consideraciones finales}

El análisis comparativo de La luz difícil y La balada del pajarillo, a la luz de las referencias críticas propuestas y las alusiones a la tradición de la novela que acompañan el artículo, permiten comprender tres aspectos de interés: 1) características que se encuentran en las narraciones que constituyen los orígenes de la novela de artista y aquellas propuestas por González y Espinosa; 2) un elemento común que supone una apreciación del arte como inherente al artista/héroe de la novela; 3) por último, el concepto de la novela como ejercicio liberador y catártico del artista, sumándole a esto que ambos protagonistas pueden comprenderse como alter ego de sus autores. Antes de revisar estas observaciones conviene honrar a la tradición con una cita de Marcuse:

El análisis de la novela de artista, por lo tanto, necesita rastrear los esbozos generales de la vida cultural, y solo en las primeras etapas, en donde una nueva subjetividad liberada emerge, la novela de artista expone, fundamentalmente, una fortaleza lírica o autobiográfica de calidad. (2007, p. 79)

David y Braulio son, en efecto, dos personalidades peculiares que llevan una forma de vida diferente a aquella impuesta por la sociedad (Marcuse, 2007, p. 74). Además, ambos se caracterizan por vivir de manera sobrehumana, pues las limitaciones del hombre común no les competen o, por lo menos, no los angustian como al resto. Ahora, las diferencias con aquellos textos propios de la tradición de la novela se presentan debido a un efecto evolutivo de dicha tradición. Es decir, La luz difícil y La balada del pajarillo no tienen la función histórica de una Bildungsroman, como en el caso de Goethe, ni buscan exponer las características más notorias de una Künstlerroman, como en el caso de Enrique de Ofterdingen, de Novalis. Son, en realidad, el resultado de narraciones contemporáneas provistas de descripciones identificables por el lector y que tienen a un artista como protagonista. Sin embargo, a pesar de que el tiempo y el lenguaje cambian, las angustias del artista en esta tradición siguen vigentes.

Dicha vigencia es entendible, como factor común, en el aprecio y empeño que el artista pone en el arte y la vida. Es claro, entonces, que en Los años de aprendizaje de Wilhelm Meister la compañía de teatro trate de comprender las obras que representa: "También apreciaron este modo de penetrar en el espíritu del poeta y se propusieron leer cualquier obra que fueran a representar adentrándose en el pensamiento de su autor" (Goethe, 2003, p. 164). De igual manera, David se consagra a la espuma del ferry, motivado por el incidente de Jacobo, como si se tratase de su mejor obra. Braulio, por su parte, se deleita reviviendo la poesía provenzal como uno más de los guiños textuales que le sugiere la pintura de la cierva blanca. El arte y la vida van de la mano y no tendrían sentido, en ocasiones, si se les separase.

Vale la pena resaltar el papel que tiene el arte en la novela, como liberador del artista. En Los años de aprendizaje de Wilhelm Meister, la vida teatral constituye un escape de la vida burguesa 
que tanto atormenta al protagonista. En Enrique de Ofterdingen (especialmente después de que el artista/héroe sobresale artísticamente) puede observarse cómo la visión de una poesía universal pretende liberar al mundo: "el artista es, ahora, algo más que un esteta, se ha convertido en redentor" (Hahn, 2002, p. 40). David, en La luz difícil, reconoce, en el ejercicio catártico de sus memorias, una forma de salvación en la escritura, manifiesta en la ortografía de Ángela como algo “iMarabilloso!” (González, 2011, p. 132). Y, por último, en La balada del pajarillo, Braulio, no solo se libera por medio de los manuscritos que narran su vida en los años noventa, sino que también lo hace, desde la cárcel, al publicar los poemas de Mabel.

Ahora, la vivienda del pintor retirado en La luz difícil arroja luces autobiográficas, o por lo menos extensiones de la experiencia, si se relaciona con el tiempo que González vivió en Nueva York: "El apartamento del East Village, con Cristóbal y el cementerio, es nuestro apartamento de esos años" (González, entrevistado por Vergara, 2019, p. 194), es decir, su conocimiento del lugar en el que transcurre la parte más activa del artista en la novela, en oposición a su retiro en una zona rural, condición que también comparte con los lugares de residencia en los que alguna vez moró el autor antioqueño. Por otro lado, Cendales tiene casi todas las condiciones de ser un alter ego de Espinosa, pues ya el cartagenero se había referido a él como un huésped en el prólogo a "Romanza para murciélagos" de sus Cuentos Completos (2007), reflejándose en su personaje: "fiel a su modo de ser. Su superioridad intelectual no cede ante nadie y, mucho menos, ante ninguna condición [...] culto, elegante, altivo, prepotente, al margen" (Herrera, 2018, p. 482). Por lo que se ve entre estos dos personajes, y en sus autores, hay más divergencias que similitudes. Los une, en todo caso, la necesidad de novelar a los artistas y, en cierto sentido, ficcionalizarse a sí mismos. No está de más decir que la relación entre artista y literatura, de Goethe hasta González, contiene elementos particulares de la condición del artista que, incluso en estos tiempos, merecen ser revisados.

\section{Referencias}

Álvarez, A. (1993). Ídolos rotos de Manuel Díaz Rodríguez: una tropical novela de artista. Nueva Revista de Filología Hispánica, XLI(1), 293-332.

Beebe, M. (1964). Ivory towers and sacred founts - The artist as hero in fiction from Goethe to Joyce. New York University Press.

Espinosa, G. (2000). La balada del pajarillo. Alfaguara. Espinosa, G. (2007). Cuentos completos. Alfaguara.

Garrard, P. (2009). Avoiding the archetype: reading and writing the female artist. [Tesis doctoral]. RMIT University. http://researchbank.rmit.edu.au/eserv/ rmit:10712/Garrard.pdf

Goethe, J. W. (2003). Los años de aprendizaje de Wilhelm Meister. https://biblioteca.org.ar/libros/92820.pdf

González, T. (2011). La luz difícil. Alfaguara.

Hahn, H. (2002). The artist as God: the reconciliation of religion with art in Novalis' Heinrich von Ofterdingen. En S. Slawinski y G. Tihanov (eds.), New comparison: the European Kunstlerroman (pp. 26-46). The British Comparative Literature Association.

Herrera, C. (2018). La ventaja de no pertener: Germán Espinosa(Cartagena, 1938-Bogotá, 2007). Perseitas, 6(2), 473-481. https://doi.org/10.21501/23461780.2847

Maas, W. (2002). Wilhelm Meister, romantic and modern. En S. Slawinski y G. Tihanov (eds.), New comparison: the European Kunstlerroman (pp. 14-25). The British Comparative Literature Association.

Marcuse, H. (2007). The German artist novel: Introduction. En D. Kellner (ed.), Art and liberation. Collected papers of Herbert Marcuse (Vol. IV, pp. 1-70). Routledge.

Quintero, J. (2010). El poeta en la novela hispanoamericana: una lectura de Roberto Bolaño, Sergio Ramírez, Cristian Barros y otros escritores desde el modernismo hasta hoy. Editorial Universidad de Antioquia.

Varsamopolou, E. (2002). Introduction: Two centuries of the European Künstler (in)roman. En S. Slawinski y G. Tihanov (eds.), New comparison: the European Kunstlerroman (pp. 7-13). The British Comparative Literature Association.

Vergara, A. (2019). Tomás González: el camino hacia la levedad. Estudios de Literatura Colombiana, 45, 189-199. https://doi.org/10.17533/udea.elc. n45a11 